\title{
Standards for relations of cardiothoracic surgical organizations with industry
}

Robert M. Sade, MD, for The American Association for Thoracic Surgery Ethics Committee and The Society of Thoracic Surgeons Standards and Ethics Committee

Most physicians are well aware of the interest the United States Congress, various federal agencies, and state legislatures have shown in the influence of companies that produce drugs and devices on physicians' use of these products. Recently, the focus on industry's influence in the health care field expanded to include relations with professional medical societies. In 2009, the Institute of Medicine published a report, "Conflict of Interest in Medical Research, Education, and Practice." ${ }^{1}$ Citing the growing interest in Congress and elsewhere, the authors state, "Physicians and researchers... and the institutions that carry out medical research, education, clinical care, and practice guideline development must recognize public concerns about conflicts of interest and take effective measures soon to maintain public trust" (p 16). ${ }^{1}$ Professional societies were named among those institutions. Also in 2009, a group of influential physicians, medical sociologists, and bioethicists published a paper in the Journal of the American Medical Association that focused entirely on medical specialty societies and their relations with industry. ${ }^{2}$ The authors made a series of recommendations, several of which were highly controversial. In response to this increasing scrutiny, the American Association for Thoracic Surgery (AATS) and The Society of Thoracic Surgeons (STS) charged the Ethics
Forum, which comprises the members of the AATS Ethics Committee and STS Standards and Ethics Committee, with developing a report and guidelines describing how cardiothoracic societies interact with industry. As the Ethics Forum began work on the project, it came to light that the Council of Medical Specialty Societies (CMSS) was writing a document that addressed this issue. After a process of vetting by the member societies, the "CMSS Code for Interactions With Companies" 3 was completed in the spring of 2010 and the member societies were invited to approve the document as presented. At that point, the CMSS Code contained several provisions that were deemed worthy of further consideration by STS, a member organization (the AATS was not a member), and STS abstained in the approval vote. To carry out its charge from the AATS and STS, the Ethics Forum used the CMSS Code as a model and modified it to suit the needs of cardiothoracic surgery specialty societies. By the end of January 2011, the final version was completed, and the AATS and STS adopted the "Cardiothoracic Surgical Organizations' Standards for Interactions With Companies." As official policy of both organizations, this document is being simultaneously published by The Journal of Thoracic and Cardiovascular Surgery and The Annals of Thoracic Surgery.

\footnotetext{
From The American Association for Thoracic Surgery, Beverly, Mass; and The Society of Thoracic Surgeons, Chicago, III.

This article is being published simultaneously in The Journal of Thoracic and Cardiovascular Surgery and in The Annals of Thoracic Surgery.

American Association for Thoracic Surgery Ethics Committee-Drs Robert M. Sade, Charleston, SC (Chair); Cary W. Akins, Boston, Mass; Thomas A. D'Amico, Durham, NC; James W. Jones, Houston, Tex; Martin McKneally, Toronto, Ontario, Canada; Keith Naunheim, St. Louis, Mo; and Andrew S. Wechsler, Philadelphia, $\mathrm{Pa}$; and The Society of Thoracic Surgeons Standards and Ethics CommitteeDrs Robert M. Sade, Charleston, SC (Chair); Charles R. Bridges, Philadelphia, Pa; David N. Campbell, Aurora, Colo; Kathleen N. Fenton, Memphis, Tenn; Mark K. Ferguson, Chicago, Ill; Steven W. Guyton, Seattle, Wash; John W. Hammon, Jr, Winston-Salem, NC; Leslie J. Kohman, Syracuse, NY; Jeffrey B. Kramer, Kansas City, Kan; Sidney Levitsky, Boston, Mass; Gordon F. Murray, Southport, NC; Mark B. Orringer, Ann Arbor, Mich; Ross M. Ungerleider, Portland, Ore; and Richard I. Whyte, Stanford, Calif.

Address for reprints: Robert M. Sade, MD, Division of Cardiothoracic Surgery, Department of Surgery, Institute of Human Values in Health Care, Medical University of South Carolina, 25 Courtenay Dr, Ste 7028, MSC 295, Charleston, SC 29425 (E-mail: sader@musc.edu).

J Thorac Cardiovasc Surg 2011;142:12-7

$0022-5223 / \$ 36.00$

Copyright $@ 2011$ by The American Association for Thoracic Surgery and The Society of Thoracic Surgeons

doi:10.1016/j.jtcvs.2011.04.036
} 


\section{CARDIOTHORACIC SURGICAL ORGANIZATIONS' STANDARDS FOR INTERACTIONS WITH COMPANIES*}

Cardiothoracic surgical organizations ("Societies/Associations") play an important role in reaching out to health professionals, patients, and other groups. We guide biomedical research, discover new therapies, and engage in highquality surgical practice. We offer educational opportunities that help translate scientific and medical progress into the efficient delivery of effective medical care, develop resources that guide our members in advancing the standard of care, and provide a forum for presenting new skills and scientific developments.

For-profit entities that develop, produce, market or distribute drugs, devices, services or therapies used to diagnose, treat, monitor, manage, and alleviate cardiothoracic diseases, ${ }^{\dagger}$ referred to in these Standards as "Companies," also strive to help patients live longer and healthier lives. The Companies invest resources to bring new drugs and devices out of the laboratory and to the patient while maximizing value for shareholders. Physicians and patients count on
Societies/Associations to be authoritative, independent voices in the world of science and medicine, and we believe that public confidence in our objectivity is important to carrying out our mission. We believe that our interactions with Companies must meet high ethical standards. ${ }^{\mathrm{A} 2}$

Societies/Associations' interactions with Companies may include receiving charitable donations, applying for grants in support of programmatic activities, and conducting a range of business transactions. ${ }^{\ddagger}$ In all of these interactions, Societies/Associations are committed to acting with integrity.

These Standards embody the core principles of our profession, and are intended to benefit both our members and their patients, and to improve cardiothoracic surgical care. Many of the relations and activities encouraged or required by these Standards are already in place, and those that are not will be implemented within one year after adoption.

\section{Definitions}

The following terms are defined for purposes of these Standards. The Society/Association recognizes that some of the terms may be used or defined differently by others. Some of these terms refer to types of interactions in which the Society/Association may engage with nonprofit organizations and individuals as well as with Companies.

\section{Advertising}

Advertising is a Business Transaction in which a Company pays a fee to the Society/Association in exchange for the Society/Association's publication of a promotional announcement that highlights the Company or the Company's products or services. For purposes of these Standards, Advertiser refers to a Company that purchases Advertising.

\section{Business Transaction}

A Business Transaction is an interaction between the Society/Association and a Company in which a Company pays a fee to the Society/Association in exchange for the Society/ Association's item, service, or product. Examples of Business Transactions include Company payment of fees associated with subscriptions to Society/Association publications, Advertising in Society/Association publications, registra-

\footnotetext{
*Adapted from CMSS Code for Interactions With Companies. ${ }^{\mathrm{A} 1}$

$\dagger$ Adapted from Advanced Medical Technology Association (AdvaMed). Code of Ethics on Interactions With Health Care Professionals. ${ }^{\text {A2 }}$
}

tions for Society/Association meetings, and exhibit space rental.

\section{Charitable Contribution}

A Charitable Contribution is a gift, including an in-kind gift, given by a Company to a qualified tax-exempt organization (eg, the Society/Association or an affiliated organization) for use in furthering the organization's charitable purposes and in accordance with applicable tax rules and legal standards.

\section{Clinical Practice Guideline}

A Clinical Practice Guideline is a systematically developed statement to assist practitioner and patient decisions about appropriate health care for specific clinical circumstances. As used in these Standards, the term Clinical Practice Guideline also refers to medical technology assessments, clinical opinions, and other evidence-based clinical practice tools, as well as updates to existing Clinical Practice Guidelines ("Guideline Updates").

\section{Company}

A Company is a for-profit entity that develops, produces, markets, or distributes drugs, devices, services or therapies used to diagnose, treat, monitor, manage, and alleviate

†These Standards do not address Societies/Associations’ interactions with nonprofit entities or entities outside of the health care sector. 
health conditions. ${ }^{\mathrm{A} 3, \mathrm{~A} 4}$ This definition is not intended to include nonprofit entities, entities outside of the health care sector, or entities through which physicians provide clinical services directly to patients.

\section{Continuing Medical Education (CME)}

Continuing Medical Education (CME) consists of educational activities for which the attendee may receive CME credit (American Medical Association [AMA] Physician's Recognition Award Credit, American Academy of Family Physicians [AAFP] Prescribed or Elective Credit, American Osteopathic Association [AOA] Credit-various categories) based on accreditation awarded to the provider by a recognized accrediting body (eg, Accreditation Council for Continuing Medical Education [ACCME], AOA, AAFP). CME activities "serve to maintain, develop, or increase the knowledge, skills, and professional performance and relationships that a physician uses to provide services for patients, the public, or the profession. ${ }^{\mathrm{A} 5, \mathrm{~A} 6}$ For purposes of these Standards, educational activities for physicians that are not CME-accredited are considered Non-CME Educational/Informational Programs.

\section{Corporate Sponsorship}

A Corporate Sponsorship is an arrangement in which a Company, typically through its marketing department, provides monetary or in-kind support for a particular Society/ Association product, service, or event, and is then acknowledged in connection with the product, service or event. Corporate Sponsorships are distinct from Educational Grants, and do not constitute Commercial Support of CME. For purposes of these Standards, Corporate Sponsor refers to a Company that provides a Corporate Sponsorship.

\section{Educational Grant}

An Educational Grant is a sum awarded by a Company, typically through its grants office, for the specific purpose of supporting an educational or scientific activity offered by the Society/Association. Educational Grants awarded by a Company to support a CME activity are referred to in the ACCME Standards for Commercial Support as "Commercial Support" of CME. ${ }^{\mathrm{A} 7}$ An Educational Grant may also be "in-kind."

\section{Key Society/Association Leaders}

The Key Society/Association Leaders include officers in the Presidential line of succession (eg, the President-Elect, the President, and the Immediate Past President) of the Society/Association's membership organization, the chief executive officer of the Society/Association's membership organization, the Editor-in-Chief of the Society/Association's journal, and others the Society/Association may designate.

\section{Non-CME Informational/Educational Program}

A Non-CME Informational/Educational Program is a program offered by the Society/Association, Company or other third party that provides educational or promotional information and does not offer CME credit.

\section{Research Grant}

A Research Grant is an award that is given by the Society/Association to an individual, institution or practice to fund the conduct of scientific research. Companies may provide the Society/Association with programmatic support (eg, an Educational Grant or Charitable Contribution) designated for the specific purpose of funding Research Grants.

\section{Satellite CME Symposium}

A Satellite CME Symposium is a Company-supported CME program held as an adjunct to the Society/Association meeting where CME credit for the Symposium is provided by a third party CME provider, and for which the Society/ Association receives a fee.

\section{Society/Association CME}

Society/Association CME refers to CME programs that are planned by the Society/Association and for which the Society/Association, as an accredited CME provider, provides CME credit.

\section{Society/Association Journal}

The Society/Association journal is a peer-reviewed scientific journal published by the Society/Association or by a publisher on the Society/Association's behalf.

\section{Standards for Interaction}

\section{Independence From Company Influence}

1.1. The Society/Association develops all educational activities, scientific programs, products, services and advocacy positions independent of Company influence, and develops and adopts policies and procedures that foster independence.
1.2. The Society/Association separates its efforts to seek Educational Grants, Corporate Sponsorships, Charitable Contributions, and support for Research Grants from its programmatic decisions, assessing the availability of funds only after independently determining that a program is needed (eg, to address gaps in care or knowledge). 
1.3. The Society/Association has identified the high-level group responsible for guiding Society/Association interactions with Companies.

1.4. The Society/Association uses written agreements with Companies for Educational Grants, Corporate Sponsorships, Charitable Contributions, Business Transactions, and support of Research Grants. These agreements specify the purpose of the funds, the amount given, the term of the agreement, and the separate roles of the Company and the Society/Association. Such agreements show that a transaction is "arms length," establish clear parameters for the use of funds, and affirm the independence of the Society/Association.

\section{Transparency}

2.1. The Society/Association's conflict of interest policies and forms are available to its members and the public.

2.2. The Society/Association discloses Company support, including Educational Grants, Corporate Sponsorships, Charitable Contributions, and support of Research Grants, making this information available to its members and the public.

2.3. The Society/Association has written disclosure policies for Key Society/Association Leaders, Board members, committee members and others who serve on its behalf, and uses the disclosed information to manage conflicts of interest in decision making. The Society/Association requires volunteers to update disclosure information at least annually and when material changes occur.

2.4. The Society/Association discloses all financial and uncompensated relationships that Key Society/Association Leaders and members of the Board of Directors of the Society/Association's membership organization have with Companies, making this information available to its members and the public.

\section{Accepting Charitable Contributions}

3.1. The Society/Association controls the use of Charitable Contributions in a manner that is aligned with the Society/Association's strategic plan and mission.

3.2. The Society/Association accepts reasonable requirements for reporting on the uses of the donated funds and reasonable restrictions on the purposes for which Charitable Contributions will be used, but declines Charitable Contributions if donor restrictions would influence Society/ Association programs or advocacy positions in a manner that is inconsistent with the Society/Association's mission.

3.3. The Society/Association has policies for consistent and appropriate recognition of donors.

\section{Accepting Corporate Sponsorships}

4.1. The Society/Association declines Corporate Sponsorship of an item or program if the item or program is inconsistent with the Society/Association's strategic plan and mission.

4.2. The Society/Association does not place the names or logos of Companies or products on Society/Association- distributed "reminder" items (eg, tote bags, lanyards, highlighters, notebooks, and luggage tags). $\S$

4.3. Corporate Sponsors of Society/Association data registries are not allowed to participate in the management of such registries in any way.

\section{Society/Association Meetings}

5.1. Educational Grants and Society/Association CME

5.1.1. The Society/Association complies with all ACCME Standards for Commercial Support, including by adopting policies and procedures designed to identify and manage conflicts of interest in Company-supported Society/Association CME programs.

5.1.2. The Society/Association retains control over the use of Educational Grants and implements safeguards designed to ensure that educational programs are nonpromotional and free from commercial influence and bias.

5.1.3. The Society/Association appoints its own planning committees to select the objectives, content, faculty, and format of educational activities in a manner that is consistent with the Society/Association mission.

5.1.4. The Society/Association does not solicit supporters' suggestions about program topics, speakers, or content.

5.1.5. The Society/Association prohibits presenters from using slides with Company logos.

5.1.6. The Society/Association requires presenters in Society CME programs to give a balanced view of therapeutic options, and encourages presenters to use generic names in place of product trade names.

5.1.7. The Society/Association does not seek support for product-specific topics.

5.1.8. The Society/Association makes reasonable efforts to achieve a balanced portfolio of support for each Society/ Association CME program.

\subsection{CME-Accredited Satellite Symposia}

5.2.1. The Society/Association requires Satellite CME Symposia to undergo an application process. $\|$

5.2.2. The Society/Association requires Satellite CME Symposia to comply with ACCME Standards.

5.2.3. The Society/Association distinguishes Satellite CME Symposia from Society/Association CME in meeting programs and promotional materials and requires third party organizers of Satellite CME Symposia to do the same.

\footnotetext{
§The Pharmaceutical Research and Manufacturers of America (PhRMA) Code on Interactions With Health Care Professionals ${ }^{\mathrm{A} 8}$ and the Advanced Medical Technology Association (AdvaMed) Code of Ethics on Interactions With Health Care Professionals $^{\mathrm{A} 3}$ do not permit Companies to give promotional, noneducational "reminder" items directly to health care professionals.

||See Definition of Satellite CME Symposium. Based on the definition of Satellite CME Symposium, Section 5.2 of these Standards does not apply to programs that are held adjunct to Society/Association meetings but (1) are not Company-supported; (2) are not CME accredited; or (3) for which the Society/Association does not receive a fee.
} 
5.2.4. The Society/Association does not permit Key Society Leaders to participate in Satellite CME Symposia as faculty members, presenters, chairs, consultants, or in any other role besides that of an attendee who receives no honoraria or reimbursement.

\subsection{Non-CME Informational/Educational Programs}

5.3.1. The Society/Association requires Non-CME Informational/Educational Programs to be clearly distinguished from Society/Association CME.

5.3.2. Key Society/Association Leaders may not participate as leaders or presenters in Company promotional/marketing events.

\subsection{Exhibits}

5.4.1. The Society/Association has written policies that govern the nature of exhibits and the conduct of exhibitors, including requiring exhibitors to comply with applicable laws, regulations, and guidance.

\section{Awarding of Research Grants}

6.1. The Society/Association does not permit Companies to select (or influence the selection of) recipients of Research Grants.

6.2. The Society/Association appoints its own committees to select recipients of Research Grants based on peer review of grant applications.

6.3. The Society/Association does not require recipients of Research Grants to meet with Company supporters.

6.4. The Society/Association does not permit Companies that support Research Grants to receive intellectual property rights or royalties arising out of the grant-funded research.

6.5. The Society/Association does not permit Companies that support Research Grants to control or influence manuscripts that arise from the grant-funded research.

6.6. The Society/Association discloses Company programmatic support (eg, an Educational Grant or Charitable Contribution) for the Society's own research. The Society/ Association acts independently in selecting research topics and conducting the research itself.

\section{Clinical Practice Guidelines}

7.1. The Society/Association bases Clinical Practice Guidelines on scientific evidence.

7.2. The Society/Association follows a transparent Clinical Practice Guideline development process that is not subject to Company influence. For Clinical Practice Guidelines and Guideline Updates developed after adoption of these Standards, the Society/Association will publish a description of its Guideline development process, including its process for identifying and managing conflicts of interest.
7.3. The Society/Association does not permit direct Company support of the development of Clinical Practice Guidelines or Guideline Updates. $\uparrow$

7.4. The Society/Association does not permit direct Company support for the initial printing, publication, and distribution of Clinical Practice Guidelines or Guideline Updates. After initial development, printing, publication and distribution is complete, the Society/Association may accept Company support for the Society/Association's further distribution of the Guideline or Guideline Update, translation of the Guideline or Guideline Update, or repurposing of the Guideline content.

7.5. The Society/Association requires all Guideline development panel members to disclose relevant relationships prior to panel deliberations, and to update their disclosures throughout the Guideline development process.

7.6. The Society/Association has procedures for determining whether financial or other relationships between Guideline development panel members and Companies constitute conflicts of interest relevant to the subject matter of the Guideline, as well as management strategies that minimize the risk of actual and perceived bias if panel members do have conflicts.\#

7.7. The Society/Association requires that a majority of Guideline development panel members are free of conflicts of interest relevant to the subject matter of the Guideline.**

7.8. The Society/Association requires the panel chair (or at least one chair if there are co-chairs) to be free of conflicts of interest with respect to topics covered within the Guideline, and to remain free of conflicts of interest for at least one year after Guideline publication. $\dagger \dagger$

7.9. The Society/Association requires that Clinical Practice Guideline recommendations be subject to multiple levels of review, including rigorous peer review by a range of experts. The Society/Association does not select as a reviewer any individual employed by or engaged to represent a Company.

\footnotetext{
TThe Society/Association does not accept Corporate Sponsorship, Educational Grants, Charitable Contributions, support of Research Grants, or any other direct Company support of Guideline development activities. Company support of the overall mission-based activities of The Society/Association is not considered direct support of Guideline development.

\#For example, The Society/Association may decide not to permit panel members with conflicts of interest to draft text or vote on panel recommendations.

**If Guideline development panel members and chairs (see Section 7.8) have conflicts of interest at the time of adoption of these Standards, the Society/Association may permit these individuals to remain actively involved in drafting the Guideline. However, each panel for which this exception is made must meet the requirements of Section 7.7 by the time of the next Guideline Update. For the minority of panel members who are not free of conflicts, The Society/Association will apply procedures for disclosure and conflict of interest management developed in accordance with Sections 7.5 and 7.6.

$\dagger \dagger$ In addition to minimizing potential conflicts, remaining free of conflicts of interest helps to ensure that a panel chair remains eligible to participate in subsequent Guideline Updates.
} 
7.10. The Society/Association's Clinical Practice Guideline recommendations are reviewed and approved before submission for publication by at least one Society/Association body beyond the Guideline development panel.

7.11. Guideline manuscripts are subject to independent editorial review by a journal or other publication where they are first published.

7.12. The Society/Association publishes Clinical Practice Guideline development panel members' disclosure information adjacent to each Clinical Practice Guideline and identifies voting abstentions.

7.13. The Society/Association requires all Clinical Practice Guideline contributors, including expert advisors or reviewers who are not officially part of a development panel, to disclose financial or other substantive relationships that may constitute conflicts of interest, and manages such conflicts of interest.

7.14. Clinical Practice Guideline development panel members must decline offers from positively or negatively affected Companies to speak about the Guideline on behalf of the Company for one year after publication.

7.15. Clinical Practice Guideline development panel members and staff must not discuss a Guideline's development with Company employees or representatives, must not accept unpublished data from Companies, and must not permit Companies to review Clinical Practice Guidelines in draft form.

\section{The Society/Association's Journal}

8.1. The Society/Association's journal maintains editorial independence from the Society/Association and from Advertisers. $\ddagger \ddagger$

8.2. The journal requires all authors to disclose all financial and other relationships with Companies in any way related to the content of the article. This disclosure should appear on the first page of the article.

8.3. The journal requires editors and reviewers to disclose financial and other relationships with Companies, and these are made available to the public.

8.4. The journal's Editor-in-Chief has the ultimate responsibility for determining when a conflict of interest should disqualify an editor or reviewer from reviewing a manuscript, according to established policies. $\S \S$

8.5. The journal's policy prohibits submission of "ghost-written" manuscripts prepared by or on behalf of Companies.

\footnotetext{
††TEditorial independence should be consistent with accepted standards for medical publishing, such as those established by the International Committee of Medical Journal Editors (ICMJE) $)^{\mathrm{A} 9}$ and the World Association of Medical Editors (WAME). ${ }^{\mathrm{A} 10}$

$\S \S$ When establishing these policies, Society Journals may find it helpful to consult accepted standards for medical publishing, such as those established by $\mathrm{ICMJE}^{\mathrm{A} 11}$ and WAME. ${ }^{\mathrm{A} 12}$
}

\section{Standards for Advertising}

9.1. The journal has written policies governing advertising in the journal.

\section{Standards for Licensing}

10.1. The Society/Association does not permit the misuse or unauthorized modification of its licensed materials, and prohibits use of Society/Association trademarks to imply Society/Association endorsement of Company products or services.

\section{Standards Bibliography}

A1. Council of Medical Specialty Societies (CMSS). CMSS code for interactions with companies. Available at: http://www.cmss.org/uploadedFiles/Site/CMSS Policies/CMSS \%20Code \%20for \%20Interactions \%20with \%20Companies \% 204-19-10.pdf. Accessed April 13, 2011.

A2. Lo B, Field MJ, eds. Conflict of interest in medical research, education, and practice. Institute of Medicine, Washington, DC: National Academy Press; 2009.

A3. Advanced Medical Technology Association (AdvaMed). Code of ethics on interactions with health care professionals. Available at: http://www.advamed.org/ MemberPortal/About/code/. Accessed April 13, 2011.

A4. Accreditation Council for Continuing Medical Education (ACCME). Definition of commercial interest. Available at: http://www.accme.org/index.cfm/fa/Policy. policy/Policy_id/9456ae6f-61b5-4e80-a330-7d85d5e68421.cfm. Accessed April 13, 2011.

A5. Accreditation Council for Continuing Medical Education (ACCME). CME content. Available at: http://www.accme.org/index.cfm/fa/Policy.policy/Policy_id/ 16f1c694-d03b-4241-bd1a-44b2d072dc5e.cfm. Accessed April 13, 2011.

A6. American Medical Association (AMA). The Physician Recognition Award and credit system. Available at: http://www.ama-assn.org/ama1/pub/upload/mm/ 455/pra2006.pdf. Accessed April 13, 2011.

A7. Accreditation Council for Continuing Medical Education (ACCME). Standards for commercial support. Available at: http://www.accme.org/dir_docs/doc upload/68b2902a-fb73-44d1-8725-80a1504e520c_uploaddocument.pdf. Accessed April 13, 2011

A8. Pharmaceutical Research Manufacturers of America (PhRMA). Code on interactions with health care professionals. Available at: http://www.phrma.org/ about/principles-guidelines/code-interactions-healthcareprofessionals. Accessed April 13, 2011

A9. International Committee of Medical Journal Editors (ICMJE). Uniform requirements for manuscripts submitted to biomedical journals: Ethical considerations in the conduct and reporting of research: Editorship. Available at: http://www. icmje.org/ethical_2editor.html. Accessed April 13, 2011.

A10. World Association of Medical Editors (WAME). The responsibilities of medical editors. Available at: http://www.wame.org/resources/policies\# responsibilities. Accessed April 13, 2011.

A11. International Committee of Medical Journal Editors (ICMJE). Uniform requirements for manuscripts submitted to biomedical journals: ethical considerations in the conduct and reporting of research: conflict of interest. Available at: http://www.icmje.org/ethical_4conflicts.html. Accessed April 13, 2011.

A12. World Association of Medical Editors (WAME). Conflict of interest in peerreviewed medical journals. Available at: http://www.wame.org/conflict-ofinterest-in-peer-reviewedmedical-journals. Accessed April 13, 2011.

\section{References}

1. Lo B, Field MJ, eds. Conflict of interest in medical research, education, and practice. Institute of Medicine, Washington, DC: National Academy Press; 2009.

2. Rothman DJ, McDonald WJ, Berkowitz CD, et al. Professional medical associations and their relationships with industry. J Am Med Assoc. 2009;301:1367-72.

3. Council of Medical Specialty Societies (CMSS). CMSS code for interactions with companies. Available at: http://www.cmss.org/uploadedFiles/Site/CMSS_ Policies/CMSS \% 20Code \% 20for \% 20Interactions \% 20with \%20Companies \% 204-19-10.pdf. Accessed April 13, 2011. 